\title{
Working fluid selection for organic Rankine cycles - Impact of uncertainty of fluid properties
}

Frutiger, Jerome; Andreasen, Jesper Graa; Liu , Wei; Spliethoff, Hartmut; Haglind, Fredrik; Abildskov, Jens; Sin, Gürkan

\section{Published in:}

Energy

Link to article, DOI:

10.1016/j.energy.2016.05.010

Publication date:

2016

Document Version

Peer reviewed version

Link back to DTU Orbit

Citation (APA):

Frutiger, J., Andreasen, J. G., Liu , W., Spliethoff, H., Haglind, F., Abildskov, J., \& Sin, G. (2016). Working fluid selection for organic Rankine cycles - Impact of uncertainty of fluid properties. Energy, 109, 987-997.

https://doi.org/10.1016/j.energy.2016.05.010

\section{General rights}

Copyright and moral rights for the publications made accessible in the public portal are retained by the authors and/or other copyright owners and it is a condition of accessing publications that users recognise and abide by the legal requirements associated with these rights.

- Users may download and print one copy of any publication from the public portal for the purpose of private study or research.

- You may not further distribute the material or use it for any profit-making activity or commercial gain

- You may freely distribute the URL identifying the publication in the public portal 


\section{Working fluid selection for organic Rankine cycles - impact of uncertainty of fluid properties}

Jérôme Frutiger ${ }^{a}$, Jesper Andreasen ${ }^{b}$, Wei Liu ${ }^{c}$, Hartmut Spliethoff ${ }^{c}$, Fredrik Haglind ${ }^{b}$, Jens Abildskov ${ }^{a}$, Gürkan Sin ${ }^{a^{*}}$

a) The CAPEC-PROCESS Research Center, Department of Chemical and Biochemical Engineering, Technical University of Denmark (DTU), Søltofts Plads, Building 229, DK-2800 Kgs. Lyngby, Denmark

b) Section of Thermal Energy, Department of Mechanical Engineering, Technical University of Denmark (DTU), Nils Koppels Allé, Building 403, DK-2800 Kgs. Lyngby, Denmark

c) Institute for Energy Systems, Technische Universität München, Boltzmannstrasse 15, DE85748 Garching, Germany

*corresponding author

\section{ABSTRACT:}

This study presents a generic methodology to select working fluids for Organic Rankine Cycles (ORC) taking into account property uncertainties of the working fluids. A Monte Carlo procedure is described as a tool to propagate the influence of the input uncertainty of the fluid parameters on the ORC model output, and provides the 95\%-confidence interval of the net power output with respect to the fluid property uncertainties. The methodology has been applied to a molecular design problem for an ORC using a low-temperature heat source and consisted of the 
following four parts: 1) formulation of process models and constraints 2) selection of property models, i.e. Peng-Robinson equation of state 3) screening of 1965 possible working fluid candidates including identification of optimal process parameters based on Monte Carlo sampling 4) propagating uncertainty of fluid parameters to the ORC net power output. The net power outputs of all the feasible working fluids were ranked including their uncertainties. The method could propagate and quantify the input property uncertainty of the fluid property parameters to the ORC model, giving an additional dimension to the fluid selection process. In the given analysis 15 fluids had an improved performance compared to the base case working fluid. 


\section{Introduction}

In recent years the focus on utilization of low-temperature heat sources in different applications such as waste heat in chemical industries and refrigeration plants as well as renewable energy sources such as biomass combustion, geothermal and solar heat sources has increased. The ORC power plant is an important technology to convert this heat into usable work, because it can be applied to a variety of heat sources and a wide range of temperatures [1]. When optimizing the performance of the ORC system it is vital to consider the influence of the working fluid, the component design and the operating conditions. In the early design stage multi-criteria database search and Computer Aided Molecular Design (CAMD) can be applied to generate, test and evaluate promising pure component and mixture candidates as working fluids to help optimize cycle design and performance. Generally speaking CAMD tries to identify the best suitable molecule subject to desired target properties of a defined system.

Database searches and other CAMD methodologies rely crucially on experimental and predicted property data. In the preliminary design stage, a large amount of property data is usually either screened or generated and tested. However, these data are subject to uncertainty, e.g. caused by the measurements [2] or by the property prediction models [3]. In particular the widely used group contribution (GC) models can be subject to varying uncertainty depending on the compound [4]. In the scope of good modeling practices (GMoP), it is necessary to take these property uncertainties into account in order to establish the application range and the reliability of the overall design model [5]. However, there is still a lack of uncertainty analysis methods due to property uncertainty in complex molecular design problems, especially in the domain of working fluid selection and design [6]. Maranas [7] described optimal molecular design considering uncertainty of nonlinear structure-property functionalities. Kim et al. [8] studied the 
selection of solvents for chemical downstream processes (i.e. extraction) considering uncertainties associated with property estimation. Martín et al. [9] addressed uncertainties due to external factors (e.g. product price) and internal factors in the design of formulated products. Recently the effects of property prediction uncertainty in product design has been considered via the approach of fuzzy optimization [10][11].

The reviews on fluid selection provided by Bao et al. [12] and fluid design studies by Linke et al. [13] give a broad overview of the abundant literature, which is available on working fluids for ORCs. Recently the combination of fluid design and selection with cycle process optimization has become established as a promising approach to achieve high net power outputs for ORCs with low-temperature heat sources [14]. Chys et al. [15] optimized the process parameters of a large number of working fluids (pure fluids, binary mixtures and three-component mixtures) in low-temperature ORCs to reach maximum thermal efficiency. Andreasen et al. [16] performed a fluid selection and optimization study of ORCs from a low-temperature heat source, considering a large group of binary mixtures as possible working fluids, combined with an evaluation of parameters which affect the design of components. Luo et al. [17] evaluated working fluids with low Global Warming Potential (GWP) in the context of different resource temperatures. Based on a variety of technical, economic and safety-related criteria Rödder et al. [18] selected fluids for a two-stage cycle consisting of a high and low temperature part. Chys et al. [15], Andreasen et al. [16], Luo et al. [17], Rödder et al. [18] used the well-established REFPROP database [19] as source for thermodynamic property data. REFPROP provides uncertainties on measurable quantities like heat capacities, speed of sound and densities. The uncertainties are specific for each fluid and based on the reference where the corresponding data is from. However, there is no information on propagated uncertainty on the corresponding enthalpy or entropy output. 
Brown et al. [20] applied the Peng-Robinson equation of state (EoS) to screen the performance potentials of many thousands of working fluids in ORCs. The same authors also varied the fluid parameters of the Peng-Robinson EoS in order to investigate theoretically ideal working fluids [21]. Predicted and experimental property data were used, without propagating its uncertainty to the model output. Stijepovic et al. [22] explored the relationship between working fluid properties and economic and thermodynamic ORC performance criteria. Huixing et al. [23] analyzed the influence of working fluid properties on the ORC cycle performance by optimizing their system for a variety of hydro carbons and hydro fluorocarbons. Desideri et al. [24], Hærvig et al. [25] and Xu et al. [26] studied the influence of the critical temperature of the working fluid on the ORC performance.

Furthermore, there is a variety of studies [27][28][29] that screened working fluid candidates using property data from the well-established DIPPR 801 AIChE database [30] for ORCs with low and high temperature heat sources. For example Drescher and Brüggemann [27] used the DIPPR database for ORC fluid selection in low-temperature biomass power and heat plants. However, none of these studies integrated the data uncertainty information, which is provided by the database, into the modeling.

Papadopoulos et al. [31] used CAMD to optimize the molecular structure of pure components as well as the composition of mixtures and subsequently evaluated the optimum molecules in an ORC process by multi-objective optimization. In a further study Papadopoulos et al. [32] applied CAMD for the synthesis and selection of binary working fluid mixtures for ORC power plants and included a nonlinear sensitivity analysis method to address model-related uncertainties in the mixture selection procedure. The sensitivity analysis allowed identifying and quantifying the model parameters that mainly influence the performance of the mixture candidates in the 
ORC[32]. Palma-Flores et al. [33] used combined CAMD and process equations in a mixed integer non-linear programming (MINLP) model. Molina-Thierry [34] simultaneously optimized fluid mixtures (generated from a pre-specified set of pure fluids) and the operating conditions of an ORC. The latter three studies used Group Contributions (GCs) and standard cubic EoS in order to estimate the respective fluid properties. The sensitivity analysis method of Papadopoulos et al. [32] was specifically adapted by Mavrou et al. [35] for the identification of optimal fluid mixtures under changing design and operating parameters. Lampe et al. [36] suggested an optimization-based method for the design of optimum ORC working fluids, namely the continuous molecular targeting (CoMT-CAMD) method, which uses perturbed chain statistical associating fluid theory (PC-SAFT) EoS and quantitative structure-property relationships (QSPR) to estimate properties.

The influence of property uncertainty on the output of a complex molecular design problem, such as the identification of suitable working fluid candidates for ORC power plants, is, to our best knowledge, not yet established. All of the above mentioned studies use a variety of property models, only a few [32][35] consider explicitly the overall influence of their uncertainty on the model output. In this context we believe that the following aspects have not drawn sufficient attention in the literature:

- Implementation of property-focused uncertainty analysis into the working fluid design problem

- Usage of computationally efficient stochastic methods such as Monte Carlo procedure to account for uncertainties in design problems for working fluids

- Inclusion of uncertainty information into the selection process of working fluids 
In general there are three types of uncertainties associated with predictions of model simulation: 1) stochastic uncertainty due to stochastic components (e.g. random failure) of a simulation, 2) structural uncertainty related to the approximation of a real physical system by a (generally more simplified) mathematical model, and 3) input uncertainty representing incomplete knowledge about the fixed parameters used as input to the model [5][37]. The most frequently used uncertainty analysis methods in science and engineering are Bayesian analysis and Monte Carlo methods [38][39]. In complex numerical models the use of Bayesian analysis is emerging to perform uncertainty analysis in combination with evolutionary optimization algorithms [40].

In this study a Monte Carlo procedure is applied. Monte Carlo methods are known as wellestablished method for the propagation of input uncertainty in a variety of applications in science and engineering [41]. The basic principle is to characterize each input parameter of a model by distributions. These distributions are assumed to statistically represent the degree of belief with respect to where the appropriate values of the parameters lie. In order to combine different parameter sets, a Monte Carlo based sampling method using Latin hypercube sampling needs to be applied. Evaluating the model with respect to the parameter sets obtained by sampling from the distributions allows displaying the distribution of the model output, which provides a complete representation of the uncertainty of the model output [41].

A classical attempt is a "one-factor-at-a-time approach" by simply varying the parameters of the model individually while all other parameters remain at their nominal values. This approach however studies the local effect of the parameters in question and therefore the interpretation is valid only locally. However, Monte Carlo based procedures differ in two important ways: (i) the method consider the impact of more than one change of parameter at the time (simultaneous variation of model parameters. Hence the results do not depend on the point where the analysis is 
carried) and (ii) the method cover a wider range for parameter values (not only variation around nominal values but much larger range specified by the user). Therefore this method depicts the global effect of parameter uncertainty which helps obtain statistically meaningful analysis [41].

The uncertainty analysis methodology follows the work of Sin et al. [5]: Monte Carlo analysis of uncertainty involves three steps: (1) specifying input uncertainty (2) sampling input uncertainty and (3) propagating the sampled input uncertainty in order to obtain a prediction uncertainty for the model output (i.e. the net power output of the ORC power plant) [5].

We present a methodology as well as a pseudo-code for efficient implementation to select working fluids for ORC power plants that takes into account fluid property uncertainty. The current work aims at depicting the influence of the input uncertainty of the fluid parameters on the ORC model output. Only the uncertainty with respect to the fluid properties is considered, whereas the process parameters are kept fixed. The particular focus on the influence of property uncertainty depicts a whole new dimension of the ORC working fluid selection in the context of database search and molecular design.

The methodology consists of a cycle model using the Peng-Robinson EoS. The input property parameters for the working fluid are provided by the DIPPR 801 AIChE database[30] which states the uncertainty of experimental and predicted data. Using a Monte Carlo procedure the uncertainty of the input parameters on the model output (e.g. the net power) is assessed.

The paper is organized as follows: (i) the overall methodology is outlined; (ii) the ORC model including the used EoS and the respective property database is presented (iii) the Monte Carlo procedure used to perform uncertainty analysis and design space exploration is presented (iv) the results of the application of the methodology by screening of all the compounds of the DIPPR 
801 database are presented (v) the results are compared to those obtained when property modeling is done using the REFPROP 9.0 database [19]. 


\section{Method and Tools}

An overview of the methodology divided in different steps is shown in Table 1.

Table 1. Overview of the methodology.

\section{Step 1 Formulation of ORC process models and constraints}

\section{Step 2 Selection of equation of state and property database}

\section{Step 3 Model solution for all compounds}

Step 3.1 Sampling in process variable search space

Step 3.2 Evaluation of model for each process variable sample

Step 3.3 Identification of optimal process variables

\section{Step 4 Monte Carlo procedure for uncertainty analysis}

Step 4.1 Specification of fluid property input uncertainty

Step 4.2 Sampling of property search space

Step 4.3 Evaluation of model for each property sample

Step 4.4 Computation of 95\%-confidence interval of the net power

Step 4.5 Ranking of the fluids including uncertainty

\subsection{Step 1: Formulation of ORC process models and constraints}

The ORC process investigated in this study is sketched in Figure 1 and was based on the work of Andreasen et al. [16]. The layout consisted of four main components: a pump, a boiler (preheater, evaporator and superheater), a turbine and a condenser. Heat was provided to the cycle by a hot fluid through the boiler and heat was rejected to a coolant in the condenser. The working fluid was an organic compound, which was circulated by the pump. The base case fluid was 1,1,1,3,3-Pentafluoropropane (R245fa). At the inlet to the pump the working fluid was in a saturated liquid state at a low pressure. The working fluid was pressurized by the pump and was subsequently directed to the boiler, where it was preheated to the saturated liquid state, 
evaporated and superheated (superheating was optional). The hot pressurized vapor then entered the turbine where mechanical power was produced. The turbine was connected to a generator which converted the mechanical power to electricity. The cycle was completed by condensation of the low pressure vapor at the turbine outlet.

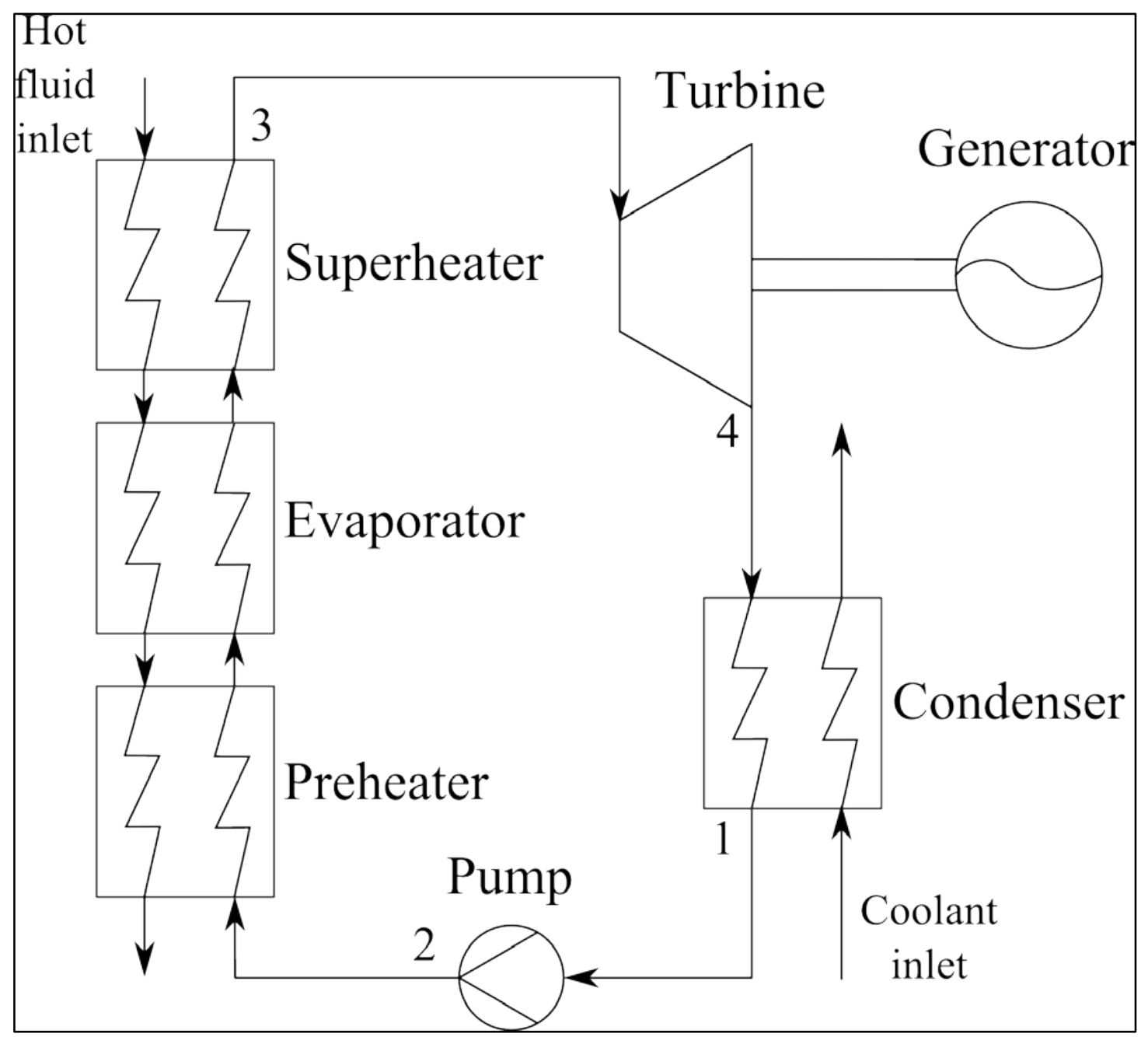

Figure 1. A sketch of the ORC process[16].

The process constraints concerning the conditions used for the hot fluid and the process components are listed in Table 2. The values were adapted from the work of Andreasen et al. [16]. The hot fluid was water at a temperature of $120{ }^{\circ} \mathrm{C}$ and a mass flow of $50 \mathrm{~kg} / \mathrm{s}$, 
representative of a waste heat stream of a chemical plant or a geothermal heat source. There were no limitations imposed on the hot fluid outlet temperature. The resulting temperature was therefore the one which ensured thermodynamically optimum conditions for the cycle. Further constraints were: 1) the minimum temperature difference in the boiler was checked at the inlet and outlet (state 2 and 3) and at the saturated liquid point, and 2) the maximum pressure in the boiler was limited at $80 \%$ of the critical pressure of the working fluid. The latter specification ensured that the cycle did not operate too close to the critical point. Hence, this avoided computational problems of the cubic EoS.

Table 2. Modelling constraints for the ORC process [16].

\begin{tabular}{l|r}
\hline Process parameter & Value \\
\hline Hot fluid inlet temperature & $120^{\circ} \mathrm{C}$ \\
Hot fluid mass flow & $50 \mathrm{~kg} / \mathrm{s}$ \\
Hot fluid pressure & $4 \mathrm{bar}$ \\
Condensation temperature & $25^{\circ} \mathrm{C}$ \\
Condenser outlet vapor quality (state 1) & 0 \\
Pump isentropic efficiency & 0.8 \\
Minimum boiler temperature difference & $10^{\circ} \mathrm{C}$ \\
Turbine isentropic efficiency & 0.8 \\
Minimum turbine outlet vapor quality (state 4) & 1 \\
\hline
\end{tabular}

The assumptions used in the numerical modeling were the following: no pressure losses in piping or heat exchangers, no mechanical or electrical losses, no heat loss from the system, steady state condition and homogeneous flow in terms of thermodynamic properties.

The output from the ORC process model was the net power output, which was the difference between the power production from the turbine and the power consumption of the pump. The net power output $\dot{W}_{N F T}$ was calculated from Eq. (1). 


$$
\dot{W}_{N E T}=\dot{m}_{w f}\left(h_{3}-h_{4}-\left(h_{2}-h_{1}\right)\right)
$$

where $h$ is the mass specific enthalpy and $\dot{m}_{w f}$ is the mass flow of the working fluid. The numbering refers to the process overview in Figure 1.

All the process equations are provided in the supporting material.

\subsection{Step 2: Selection of equation of state and property database}

The thermodynamic properties (i.e. enthalpies and entropies) required in the cycle simulations consisted of an ideal contribution (i.e. the ideal gas enthalpy and entropy) and a correction factor (departure function) accounting for the difference between ideal and real behavior. The PengRobinson Equation of State (PR EoS) [42] was selected in order to determine the departure functions of the thermodynamic properties, because of its relatively small number of required fundamental parameters as a cubic equation of state. This made it suitable for the screening of a large number of possible working fluid candidates [43]. Furthermore, PR EoS is generally known to be superior over other standard cubic EoS (e.g. Soave-Redlich-Kwong) for prediction of liquid densities [44].

The Peng-Robinson EOS is given by,

$$
p=\frac{R T}{V_{m}-b}-\frac{a \alpha}{V_{m}^{2}+2 b V_{m}-b^{2}}
$$

In Eq. (2) $R$ is the universal gas constant, $T$ is the absolute temperature, $p$ is the pressure, $V_{m}$ is the molar volume. The other parameters are defined as follows 


$$
\begin{gathered}
a=\frac{0.457235 R^{2} T_{c}^{2}}{P_{c}} \\
b=\frac{0.077796 R T_{c}}{P_{c}} \\
\alpha=\left(1+m\left(1-T_{r}^{0.5}\right)\right)^{2} \\
m=0.37464+1.54226 \omega-0.26992 \omega^{2} \\
T_{r}=\frac{T}{T_{r}}
\end{gathered}
$$

In Eq. (3) to (7) $T_{c}$ is the critical temperature, $P_{c}$ is the critical pressure, $\omega$ is the acentric factor, $T_{r}$ is the reduced temperature.

Ideal gas enthalpy and entropy changes were calculated by integrating the temperaturedependent ideal gas heat capacity. The ideal gas heat capacity correlation as defined by Aly and Lee [45] was used. Five compound-specific input parameter $(A, B, C, D, E)$ (see Eq (8)) were employed,

$$
c_{p}(T)=A+B \cdot\left[\frac{\frac{C}{T}}{\sinh \left(\frac{C}{T}\right)}\right]^{2}+D \cdot\left[\frac{\frac{E}{T}}{\cosh \left(\frac{E}{T}\right)}\right]^{2}
$$

The fluid parameters inputs for Peng-Robinson EoS were the molecular weight $M W$, the critical temperature $T_{c}$, critical pressure $P_{c}$, and the acentric factor $\omega$. Therefore, the evaluation of the thermodynamic properties required for the ORC model needed only four primary fluid properties $\left(M W, T_{c}, P_{c}, \omega\right)$ and the respective Ally-Lee heat capacity constants $(A, B, C, D, E)$. All these properties could be found in the DIPPR 808 AIChE database [30] for 1965 chemical compounds. 
The database values for $\left(T_{c}, P_{c}\right.$, and $\left.\omega\right)$ could be both experimental and predicted. DIPPR provides the Ally-Lee heat capacity constants that had been obtained by fitting the Ally-Lee correlations for each substance to the respective experimental or predicted temperature dependent heat capacity curve. The DIPPR database stated the respective uncertainty of $T_{c}, P_{c}$, and $\omega$ along with the heat capacity values obtained from the constants $A, B, C, D, E$ [46]. This information on the uncertainty was further used to calculate the output uncertainty of the net power.

The detailed property models including all equations are provided in the supporting material.

Given all the process and property equations an analysis of the degrees of freedom could be performed (see Table 3).

Table 3. Degrees of freedom analysis of the combined process and property models

\begin{tabular}{ll}
\hline Number of variables & 51 \\
\hline Number of equations & 33 \\
\hline Number of specifications & 8 \\
\hline Degrees of freedom (DOF) & 10 \\
\hline
\end{tabular}

There are 10 degrees of freedoms that needed to be fulfilled in order to solve the model. Two degrees of freedom were related to process variables:

Turbine inlet pressure $P_{t}$

Turbine inlet temperature $T_{t}$,

and 8 degrees of freedom were related to the properties of the working fluid:

Critical pressure $P_{c}$ 
Critical temperature $T_{c}$

Acentric factor $\omega$

Heat capacity constants according to Ally and Lee $A, B, C, D, E$.

The goal of the ORC model was to identify the working fluid that provided the highest net power output. Thus, the task was to identify the best parameter set $\left(P_{c}, T_{c}, \omega, A, B, C, D, E\right)$ out of 1965 compound possibilities together with corresponding optimal process parameters ( $P_{t}$ and $T_{t}$ ) that achieved the highest net power output. In that sense, the problem integrated product and process design aspects.

\subsection{Step 3: Model solution for all compounds}

We suggest the use of a sampling based approach as means to explore and identify the optimal process variables: For each of the 1965 chemical compounds (defined by the parameters $M W, T_{c}$, $P_{c}, \omega$ and $\left.A, B, C, D, E\right)$ from the DIPPR 808 AIChE database, the optimal process variables (turbine input pressure $P_{t}$ and temperature $T_{t}$ ) needed to be identified efficiently and the corresponding net power output needed to be calculated. The motivation for using Monte Carlo based sampling approach is to allow fast exploration of process design space for each working fluid candidate , which we have used as an alternative to classical optimization algorithms (e.g. particle swarm optimization)

Step 3.1: Sampling in process variable search space. The Latin hypercube sampling procedure[41] was utilized in order to obtain a number of 250 uniformly distributed pairs of process variables $P_{t}$ and $T_{t}$. The values were sampled within the predefined variable constraints in a temperature range between 25 and $110{ }^{\circ} \mathrm{C}$ (corresponding to the condensation temperature and the heat source temperature) and a pressure range between 1 and 15 bars. The lower bound 
was selected according to the minimum feasible pressure and temperature for the process, whereas the upper bound was fixed in order avoid high safety hazards and costs [27]. Subatmospheric pressure was avoided, because it might result in air infiltration, which was undesirable. Furthermore, for low temperature applications the pressures for the optimum fluids were found to be typically above atmospheric pressure [16]. The procedure of Latin hypercube sampling was used to divide the range of each variable in a certain number of equally proportioned intervals. For two variables a two-dimensional square grid was obtained. The samples were positioned such that only one sample exists in each row and each column of the grid (principle of Latin square). The generalization of this concept to more than two variables is the Latin hypercube (Step 4.2) [41].

Step 3.2: Evaluation of process variable samples. For each all of the compounds the ORC model was evaluated using the sampled pairs of process variables. Compounds that did not satisfy constraints inside the model according to Step 1 were screened out within the model evaluation. Subsequently the net power outputs of the corresponding process variable samples were ranked.

Step 3.3: Identification of optimal process variables. At this stage, the process variables giving the highest net power output were chosen to be the most favorable quasi-optimal pair of process variables $\left(P_{t}\right.$ and $\left.T_{t}\right)$ for the respective compound.

\subsection{Step 4: Monte Carlo procedure for uncertainty analysis}

For each of the feasible chemical compounds obtained from Step 3 a Monte Carlo based uncertainty analysis focusing on the input property uncertainty was performed. 
Step 4.1: Specification of fluid property input uncertainty. The input uncertainties for the parameters $T_{c}, P_{c}$ and $\omega$ were obtained from DIPPR 801 AIChE database [30]. The uncertainty provided an estimate for the standard deviation of each data point irrespective of whether it had been obtained by experiment or prediction models. For the heat capacity constants $(A, B, C, D$, E) the uncertainty of the calculated heat capacity at a certain temperature using the Ally-Lee correlation was provided. Since the uncertainties of the heat capacity constants themselves were not provided, the overall uncertainty of the calculated heat capacity needs to be taken into account in the model. Therefore, a dummy variable was introduced, which multiplied with the respective ideal gas heat capacity values. The dummy variable $d$ had the expectation value 1 and the standard deviation equal to the respective uncertainty. The input parameter space of $M W, T_{c}$, $P_{c}, \omega$ and $d$ was assumed to be normally distributed with a standard deviation equal to the uncertainty and centred around the respective database value. Table 4 showed the input property uncertainty of two selected compounds.

Table 4. Input property uncertainty of two selected compounds

\begin{tabular}{|c|c|c|c|c|c|}
\hline & \multicolumn{4}{|c|}{ Property uncertainty } & \multirow{2}{*}{$\begin{array}{l}\begin{array}{l}\text { Average } \\
\text { relative error }\end{array} \\
c_{p}(T)[\%]\end{array}$} \\
\hline & $M W[\mathrm{~g} / \mathrm{mol}]$ & $T_{C}[\mathrm{~K}]$ & $P_{c}[$ bar $]$ & $\omega[-]$ & \\
\hline $\begin{array}{l}\text { 1,1,1,3,3- } \\
\text { Pentafluoropropane }\end{array}$ & $134.0 \pm 1.0$ & $427.2 \pm 0.9$ & $36.4 \pm 3.7$ & $0.380 \pm 0.04$ & 3 \\
\hline Perfluoro-n-hexane & $338.0 \pm 1.0$ & $499.6 \pm 5.0$ & $18.0 \pm 0.9$ & $0.50 \pm 0.01$ & 10 \\
\hline References & [47] & {$[48][49]$} & {$[50][30]$} & [30] & {$[51][45]$} \\
\hline
\end{tabular}

Step 4.2: Sampling of property search space. The key step of the Monte Carlo procedure is the sampling of the parameter sets. The Latin Hypercube Sampling method was utilized for probabilistic sampling of the fluid property input space of each compound. From the input 
parameter space a total of 400 samples were selected, each sample containing one value for each input parameter. The sampling range was specified by the uncertainty (i.e. 95\%-confidence interval) range of each parameter given by the DIPPR database. The probability of uncertainty is assumed to follow normal distribution for the fluid properties, in contrast to step 3.1, where it was assumed to be uniform for the process variables. The rank-based method for correlation control of Iman and Conover [52] allowed to take into account correlations between the input parameters. This was necessary, because the Peng Robinson EoS parameters were not completely independent. The correlation matrix was directly obtained from the DIPPR data by calculating the respective correlation coefficient between the data sets. From the DIPPR data base values a correlation coefficient was statistically calculated (e.g. between $P_{c}$ and $T_{c}$ ). Such correlation coefficients are used as input in correlation-based Latin hypercube-sampling procedure. The sampling results were provided in the supporting materials. Figure 2 provided an illustration of the sampling results for the compound 1,1,1,3,3-Pentafluoropropane (R245fa). 


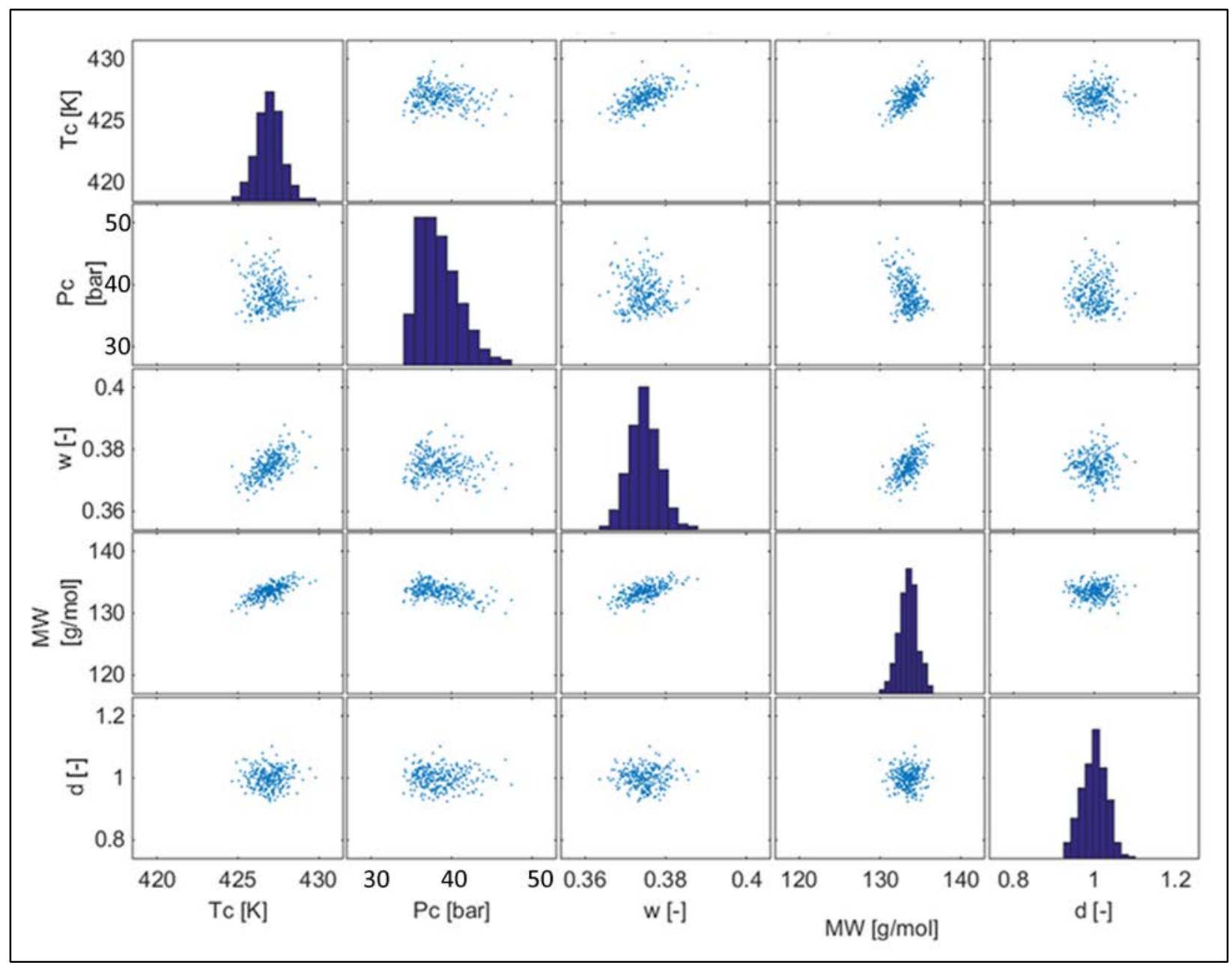

Figure 2. Illustration of samples generated by Latin Hypercube Sampling method with Iman and Conover correlation control for 1,1,1,3,3-Pentafluoropropane (R245fa).

As one can see in Figure 2, the different parameters were assumed to be normally distributed around the property value given in the database, and the width of the distribution was defined by the respective property uncertainty provided from DIPPR. The sampling plots were not uniform, because the correlation between the parameters was taken into account [52].

Step 4.3: Model evaluation for each property sample. One model simulation was performed for each of the 400 input parameter samples resulting from Step 4.2. The Monte Carlo results 
provided a cumulative distribution function for the net power output of each compound. The uncertainty of the model output could be represented in a pressure-enthalpy- and temperatureentropy-diagram.

Step 4.4: 95\%-confidence interval of the net power. Using simple statistics such as mean and percentile calculations, the 95\%-confidence interval of the net power output with respect to the corresponding input property values could be obtained for each of the compounds.

Step 4.5: Ranking of the fluids including uncertainty. The compounds were ranked according to their respective net power output including the 95\%-confidence interval. This enabled an assessment of the compounds not solely based on their actual cycle performance, but also according to the reliability of the property data used.

The results were compared to the results obtained with REFPROP 9.0 [19] for those compounds for which REFPROP parameters were known to us.

\subsection{Modeling platform}

The ORC system and the uncertainty analysis were implemented in Matlab (Mathworks, R14) [53]. The methods for performing the uncertainty analysis can be provided upon request as mscript files. Figure 3 depicts the overall methodology as pseudocode. 
Given $\mathrm{N}$ compounds from database

for compound $1: \mathrm{N}$

1) Import property data from DIPPR database

2) Check process constraints

if feasibility constraints not fulfilled

Remove compound

end

3) Sample S process variables (P,T) pairs by Latin hypercube sampling (uniform distribution) without correlation

4) for sample $1: \mathrm{S}$

Evaluate ORC model

Store net power output for every pair of process variables end

5) Rank Net power outputs

6) Select process variable pair $\left(\mathrm{P}^{\star}, \mathrm{T}^{\star}\right)$ with highest net power output as optimal end

Given $M$ feasible compounds at optimal process variables $\left(T^{\star}, P^{\star}\right)$

for feasible compound 1:M

1) Import property input uncertainty from DIPPR database

2) Sample p property values by Latin hypercube sampling normal distribution with correlation

3) for sample $1: \mathrm{P}$

Evaluate ORC model

Store net power output for every set of property variables end

4) Depict net power outputs in cumulative distribution function

5) Calculate mean and standard deviation and 95\%-confidence interval end

Rank Net power output of feasible compounds

Figure 3. Pseudocode description of the overall methodology. 


\section{Results and Discussion}

The results are structured in two parts. First the results of the uncertainty analysis are illustrated by the example of one compound, the well-established working fluid 1,1,1,3,3Pentafluoropropane (R245fa). Afterwards the results of all compounds are analysed and compared.

\subsection{Uncertainties with respect to the properties of $R 245 f a$}

Uncertainty analysis has been performed for all feasible compounds from Step 3.2 (see next section). As an example, the uncertainty analysis results for 1,1,1,3,3-Pentafluoropropane (R245fa) is given in detail. The Monte Carlo simulations obtained by simulating the 400 Latin Hypercube Samples of the property parameters resulted in 260 feasible model solutions for R245fa. The raw data obtained from the simulations can be plotted in a temperature-entropy and a logarithmic pressure-enthalpy diagram showing cycle points enumerated as in Figures 4 and 5. Each curve and design point set is different as different property parameter samples were used in each simulation. A varying band for both the saturation curves and the cycle design can be observed. From a statistical point of view the bands correspond to the distribution of the model outputs and directly show the sensitivity with respect to the fluid property values for the specific compound R245fa. The larger the width of the output range, the higher the uncertainty. Furthermore, the uncertainty in the model outputs can be represented using mean (solid line) and 95\%-confidence interval (dashed line) obtained from percentile calculations.

Since the condensation temperature of the ORC is fixed, there is no variation in the Ts-diagram in the condensation process. Similarly, there is no variation in the evaporation pressure in the Phdiagram, because the input pressure to the turbine (identified in step 3 of the methodology) is 
kept fixed. Although these process variables can be subject to uncertainty, this study focused particularly on the property parameter uncertainty.

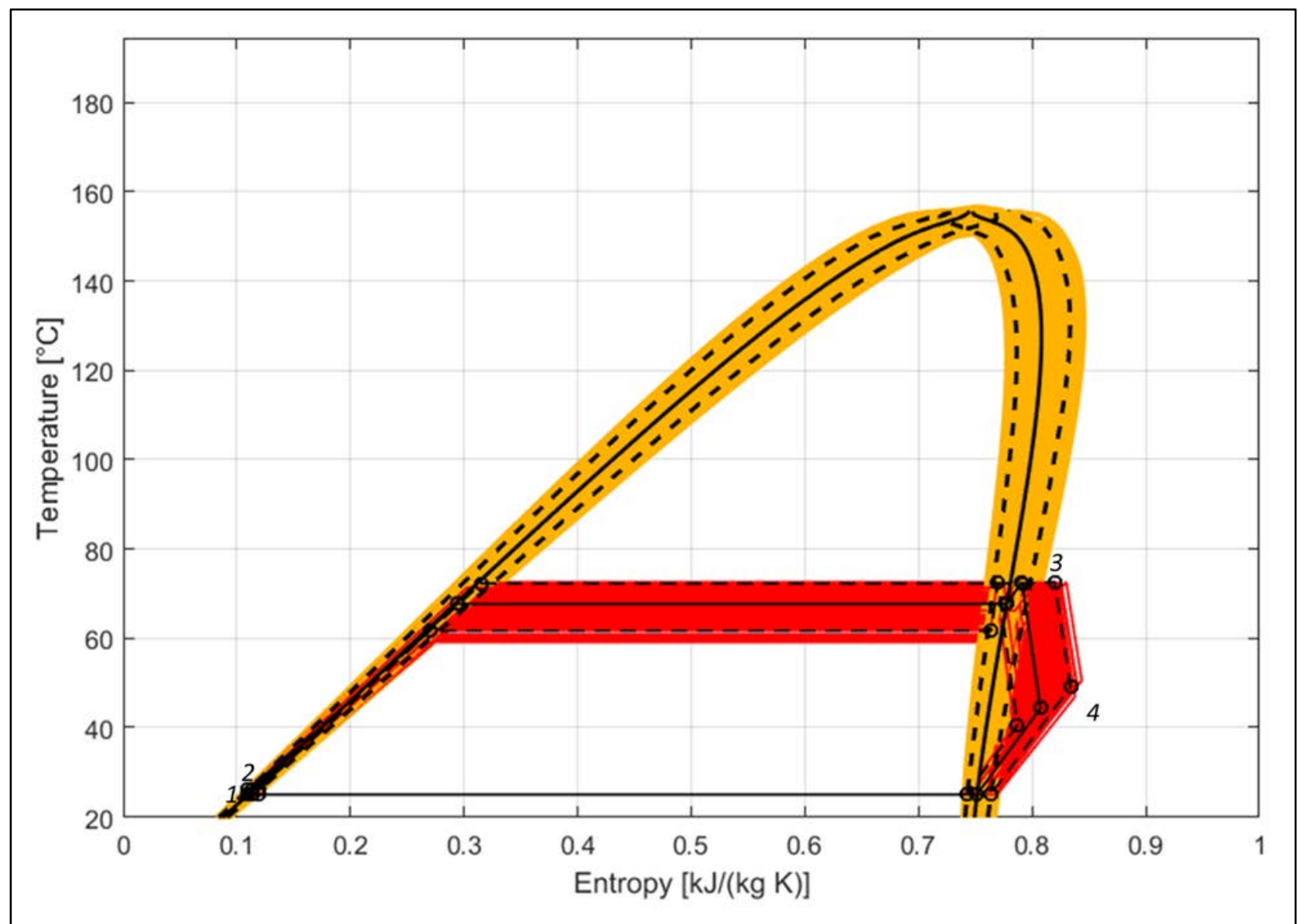

Figure 4. Representation of uncertainty with respect to the fluid properties in the Ts-diagram for R245fa: Monte Carlo simulations (yellow/red), mean (solid line) and upper as well as lower bound of the 95\%-confidence interval of the model output (dashed lines). 


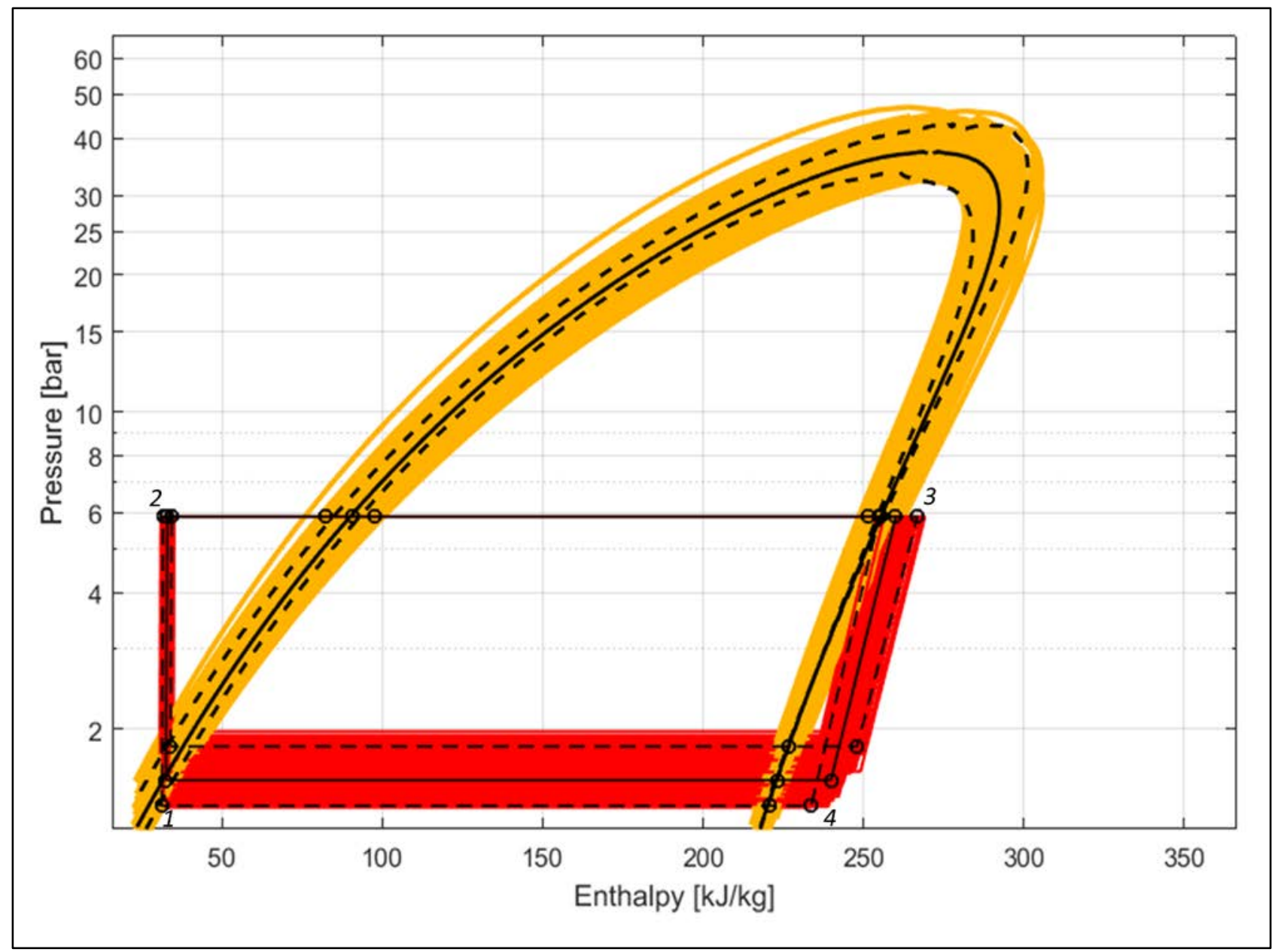

Figure 5. Representation of uncertainty with respect to the fluid properties in the Ph-diagram for R245fa: Monte Carlo simulations (yellow/red), mean (continuous line) and upper as well as lower bound of the 95\%-confidence interval of the model output (dashed lines).

For each of the simulations of R245fa the net power output can be obtained. The distribution of the net power outputs for R245fa and the corresponding empirical cumulative distribution function (empirical CDF) are two alternative representations of the uncertainty of the model with respect to the property parameters (see Figures 6 and 7). Figure 6 shows a large variety for the net power output due to property uncertainty. The gaps in Figure 6 occur, because some combinations of parameters are infeasible with respect to the property model evaluation. 


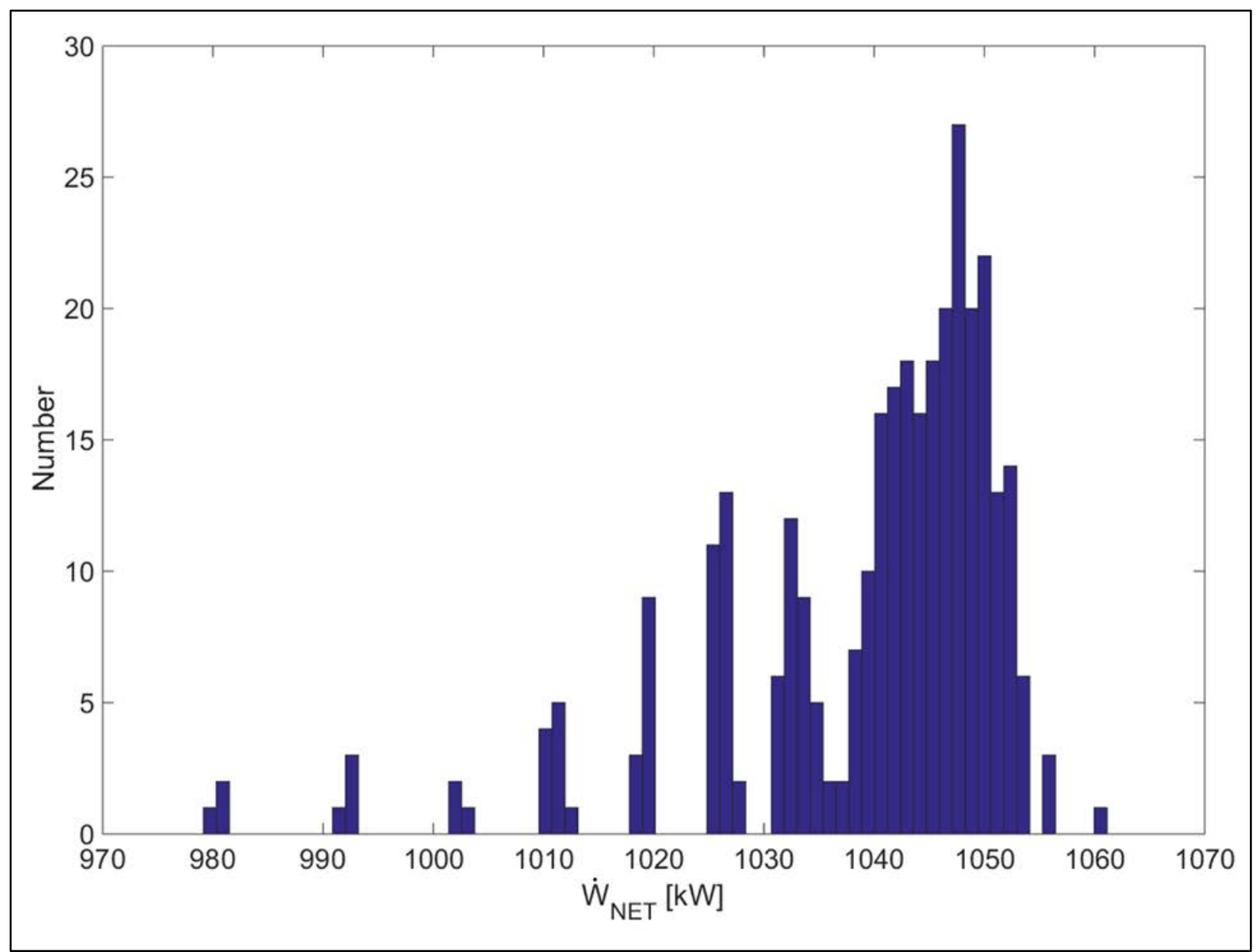

Figure 6. Distribution of the net power output $\dot{W}_{N E T}$ of the ORC for R245fa.

The empirical CDF depicted in Figure 7 is a step function that increases by $1 / \mathrm{n}$ in every data point, where $\mathrm{n}$ is the number of data points. Its aim is to estimate the true underlying distribution function. It does not a priori assume a normal distribution (or any other distribution function). The empirical CDF allows calculating 2.5\% and 97.5\% percentile defining the lower and upper bound of the 95\%-confidence for the net power output. 


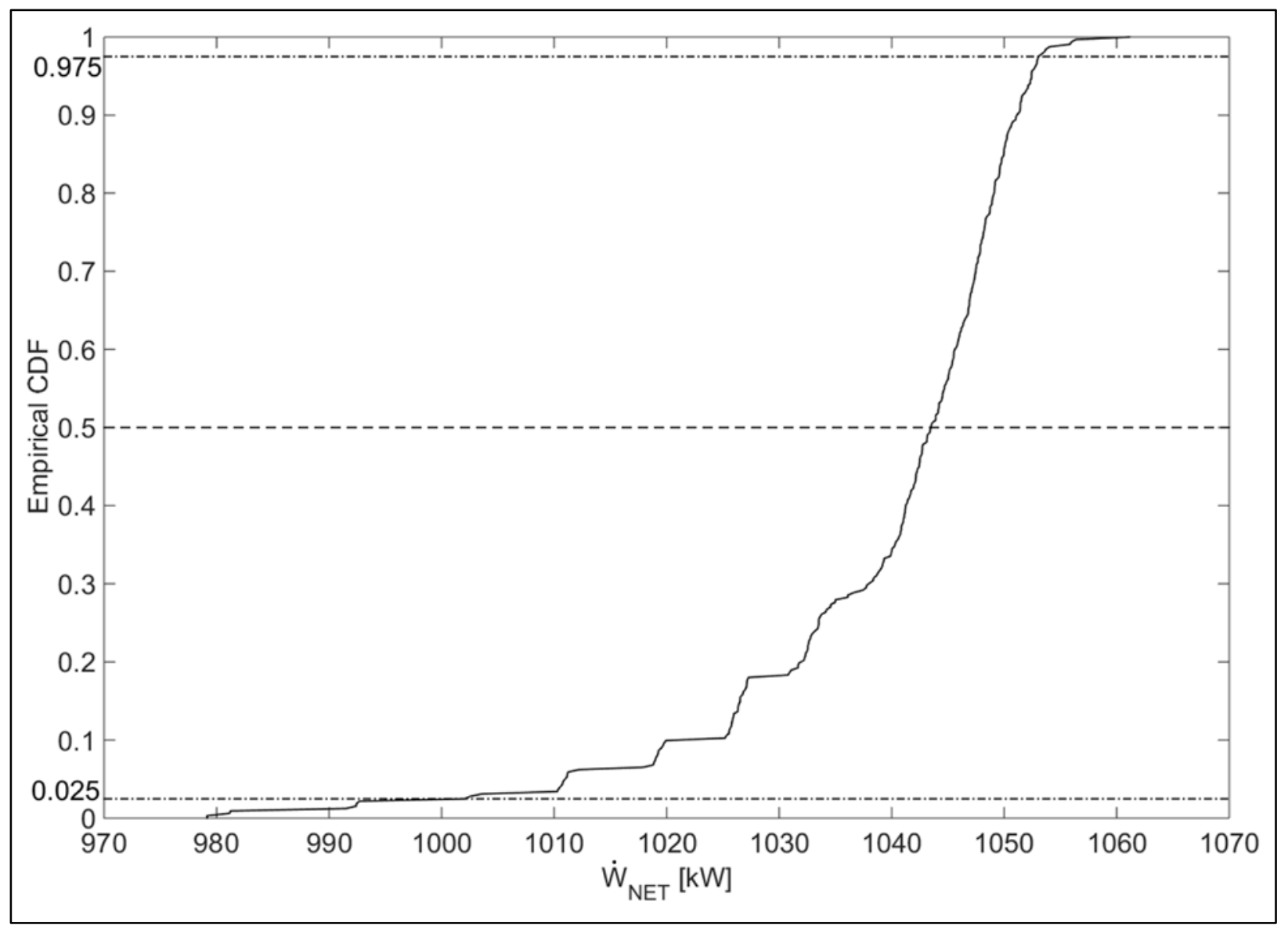

Figure 7. Empirical Cumulative Distribution Function (empirical CDF) of the net power output $\dot{W}_{N E T}$ of the ORC for R245fa with mean and 95\%-confidence interval of the model output (vertical dotted lines).

As shown in Figures 4, 5, 6 and 7, even small variations of input property parameters (Table 4) can lead to significant output uncertainty. This can be explained by the high non-linearity of the property models and process equations. The model is sensitive to different combinations of property parameters, although the importance of the individual parameters might appear to be small. It is a clear indication that the fluid property uncertainty cannot be neglected for cubic equations of state in the design of ORC, as it has been done in many previous studies and applications. This conclusion is of particular importance for CAMD problems. 
Although the study focused on the ORC process, the uncertainty analysis procedure with respect to the input parameter uncertainty can also be performed for other types of thermodynamic cycles, e.g. heat pumps.

\subsection{Ranking of working fluids including uncertainty}

Having obtained mean and 95\%-confidence interval of the net power output of all the fluids, it is possible to rank the compounds. Table 5 shows the $\dot{W}_{N E T}$ mean value of the distribution for 20 best performing compounds for the given ORC power plant including their corresponding uncertainty with respect to the property input. Furthermore, the net power outputs are compared to the values obtained by using the corresponding REFPROP correlations. The results of all feasible compounds are given in the supporting material. Furthermore, the ranking does not include safety and environmental properties of the fluid, because the particular focus of this study lies in the analysis of property uncertainty. However, it has to be acknowledged in the current case that the fluoro-compounds have a relatively high Global Warming Potential (GWP> 150) and that the hydrocarbons have a high lower flammability limit (LFL $\left.>0.1 \mathrm{~kg} / \mathrm{m}^{3}\right)$ [54]. The

mean value of $\dot{W}_{N E T}$ and the corresponding 95\%-confidence interval of the compound in Table 4 are represented in Figure 8. 
Table 5. Best performing compounds ranked by net power output including uncertainty.

\begin{tabular}{|c|c|c|c|c|c|c|}
\hline \multirow{2}{*}{$\frac{\text { Ranking }}{1}$} & \multirow{2}{*}{$\begin{array}{l}\text { Working fluid name } \\
\text { Decafluorobutane (R610) }\end{array}$} & \multirow{2}{*}{$\begin{array}{l}\text { Mean } \dot{W}_{N E T} \\
{[\mathrm{~kW}]}\end{array}$} & \multicolumn{2}{|c|}{$\begin{array}{l}\text { 95\%-conf. int. } \\
\dot{W}_{N E T}[\mathrm{~kW}]\end{array}$} & \multirow{2}{*}{$\begin{array}{l}\text { Optimal } \\
\dot{W}_{N E T}[\mathrm{~kW}] \\
\text { from Step } 3 \\
1149.2\end{array}$} & \multirow{2}{*}{$\begin{array}{l}\text { Rel. } \\
\text { deviation to } \\
\text { REFPROP } \\
9.0[\%] \\
0.56\end{array}$} \\
\hline & & & 1188.6 & 1042.6 & & \\
\hline 2 & $\begin{array}{l}\text { Octafluorocyclobutane } \\
\text { (RC318) }\end{array}$ & 1145.3 & 1174.6 & 1110.1 & 1161.7 & 0.76 \\
\hline 3 & $\begin{array}{l}\text { 2-Chloro-1,1,1,2- } \\
\text { Tetrafluoroethane (R124) }\end{array}$ & 1084.1 & 1096.7 & 1063.3 & 1083.7 & 1.01 \\
\hline 4 & Perfluoro-n-Pentane & 1068.3 & 1095.4 & 1016.3 & 1083.6 & 1.74 \\
\hline 5 & Isobutane & 1067.4 & 1074.2 & 1060.0 & 1068.4 & 0.85 \\
\hline 6 & Pentafluoroethylmethylether & 1063.0 & 1083.5 & 1038.1 & 1069.3 & $\mathrm{n} / \mathrm{a}$ \\
\hline 7 & Neopentane & 1050.8 & 1056.9 & 1043.3 & 1050.3 & 0.22 \\
\hline 8 & n-Butane (R600) & 1050.1 & 1055.7 & 1044.6 & 1049.6 & 0.44 \\
\hline 9 & $\begin{array}{l}\text { 1-Chloro-1,1-difluoroethane } \\
\text { (R142b) }\end{array}$ & 1049.1 & 1057.1 & 1031.9 & 1051.9 & 0.51 \\
\hline 10 & Isobutene & 1045.7 & 1051.6 & 1039.7 & 1048.2 & 0.32 \\
\hline 11 & Trifluoroiodomethane & 1043.3 & 1063.7 & 151.9 & 1052.1 & 1.08 \\
\hline 12 & 1-Butene & 1042.7 & 1048.6 & 1035.9 & 1039.5 & 0.03 \\
\hline 13 & $\begin{array}{l}\text { 1,1,1,2,3,3- } \\
\text { Hexafluoropropane (R236ea) }\end{array}$ & 1041.7 & 1059.1 & 1008.4 & 1051.4 & 0.01 \\
\hline 14 & $\begin{array}{l}\text { 1,1,1,2,3,3,3- } \\
\text { Heptafluoropropane (R227ea) }\end{array}$ & 1040.2 & 1199.0 & 645.4 & 1162.5 & 8.38 \\
\hline 15 & Heptafluoropropylmethylether & 1039.7 & 1046.9 & 1034.0 & 1040.5 & 0.41 \\
\hline 16 & $\begin{array}{l}\text { 1,1,1,3,3-Pentafluoropropane } \\
\text { (R245fa) - Base case }\end{array}$ & 1039.3 & 1054.5 & 1002.5 & 1050.7 & 0.71 \\
\hline 17 & trans-2-Butene & 1036.9 & 1041.5 & 1031.5 & 1041.2 & 0.34 \\
\hline 18 & $\begin{array}{l}\text { 1,2-Dichlorotetrafluoroethane } \\
\text { (R114) }\end{array}$ & 1036.2 & 1049.4 & 1010.1 & 1047.3 & 0.23 \\
\hline
\end{tabular}




\begin{tabular}{lllllll}
\hline 19 & Bis(Difluoromethyl)ether & 1035.9 & 1060.7 & 992.6 & 1048.5 & n/a \\
\hline 20 & $\begin{array}{l}\text { 1,1,1,3,3,3- } \\
\text { Hexafluoropropane (R236fa) }\end{array}$ & & & & & \\
& & & & & & \\
&
\end{tabular}

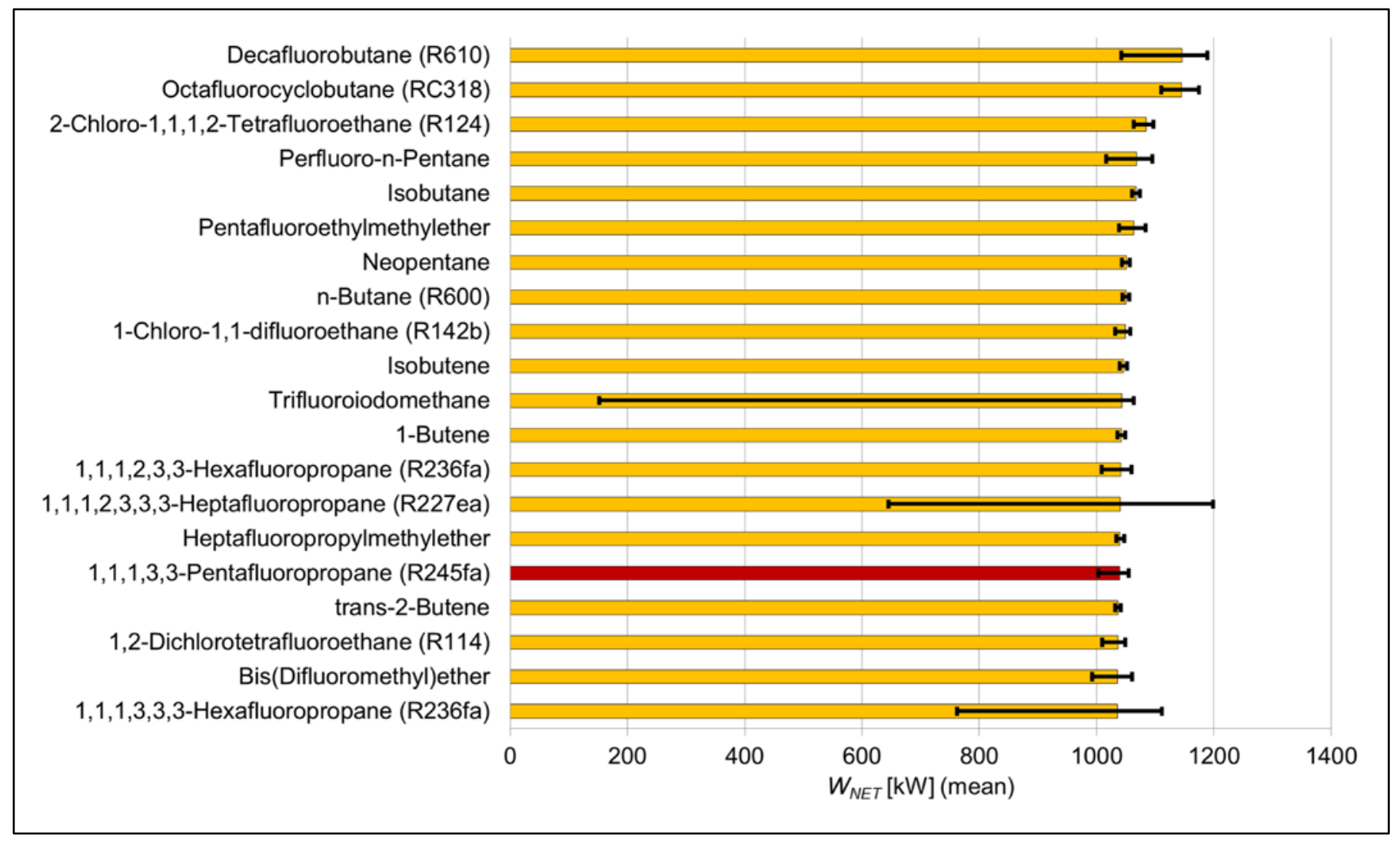

Figure 8. Mean value of the net power output $\dot{W}_{N E T}$ of the 20 best performing compounds including the 95\%-confidence interval (thin black bars) obtained from the uncertainty analysis with respect to the fluid properties. The red bar corresponds to the base case compound.

As it can be seen in Table 5, the values obtained with REFPROP have (with two exceptions) a relative deviation below $2 \%$, suggesting that the numerical models presented in this paper give reasonable results. The exceptions are 1,1,1,2,3,3,3-Heptafluoropropane (R227ea) with a deviation of 8.64\% and 1,1,1,3,3,3-Hexafluoropropane (R236fa) with 5.10\%. Both compounds also have a wide range of uncertainty. The deviation with REFPROP and the range of 
uncertainty suggest that the property data for these compounds need to be measured more accurately and reliably.

The fluids are ranked by the mean value obtained from the distribution. These values are not identical to the optimal net power output obtained in Step 3 of the methodology before the property uncertainty analysis, although the optimal value lies within the respective 95\%confidence interval. The discrepancy is a direct consequence of the fluid property uncertainty analysis. Ranking the compounds only by the optimal net power output without considering uncertainty, would be in particular give a different position for 1,1,1,2,3,3,3-Heptafluoropropane (R227ea) and 1,1,1,3,3,3-Hexafluoropropane (R236fa). Both compounds have a large optimal net power output obtained in Step 3, but due to uncertainty propagation the mean value of the net power output distribution is lower compared to the other compounds.

Alternatively the fluids can be ranked according to their respective lower bound of the $95 \%$ confidence interval (see Figure 9). This is a conservative approach of ranking and can be considered as the statistically robust way to identify promising working fluid candidates. 


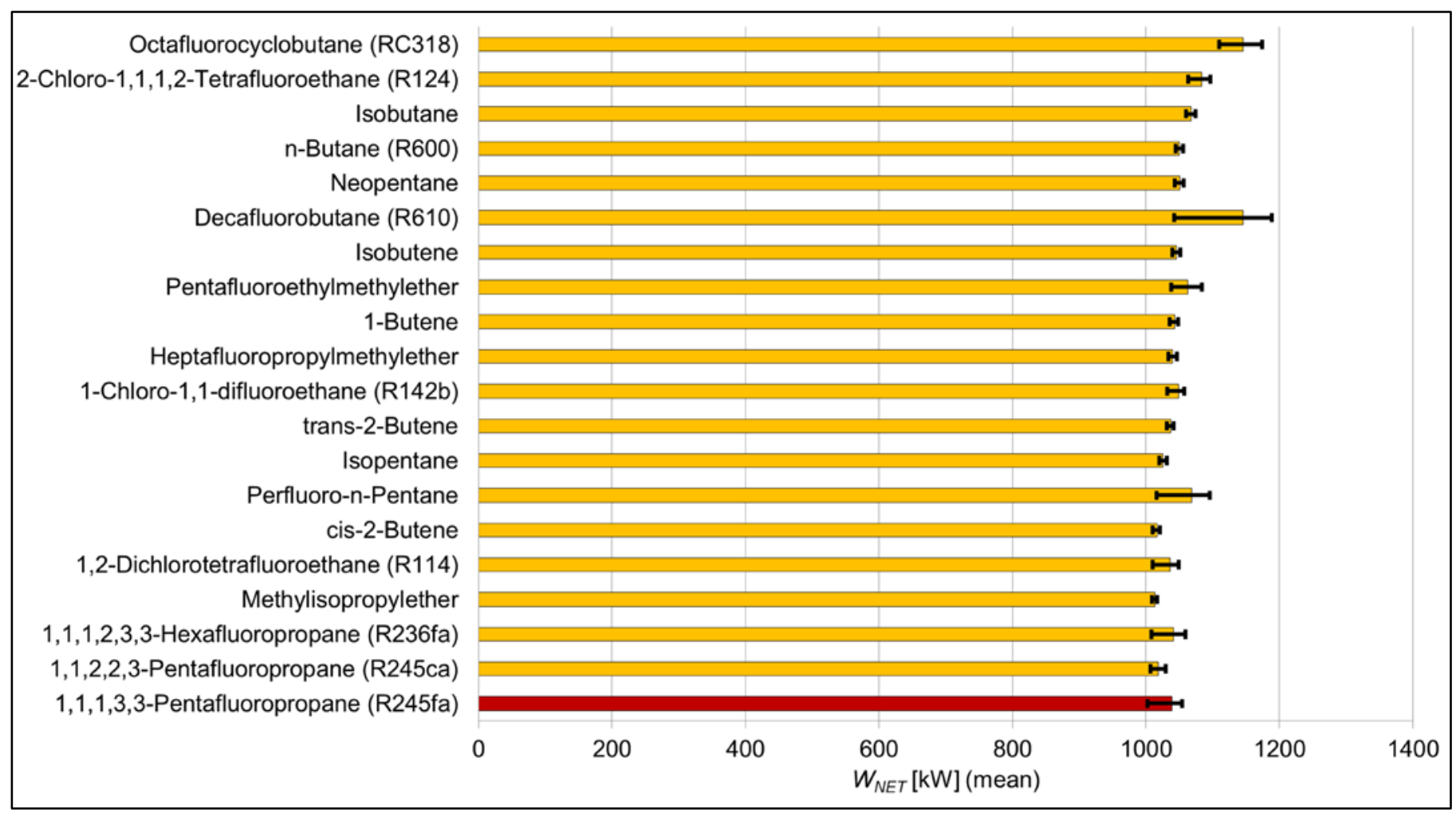

Figure 9. Ranking according to the lower bound value of the 95\%-confidence interval of the net

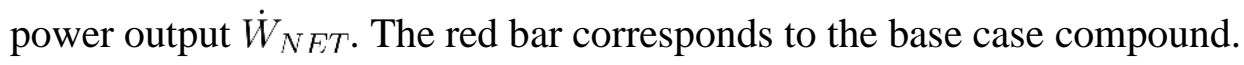

Knowing the 95\%-confidence interval of the net power output for the screened chemical compounds gives an important new dimension in the preliminary selection of suitable working fluid candidates. Some working fluids, e.g. isobutane (Compound 5 in Table 5), have a very small model output uncertainty range, whereas others, e.g. trifluoroiodomethane (Compound 11), have a very large. If the 95\%-confidence interval of a compound overlaps with the one of the base case, it is statistically impossible to say, which of two perform better. This is the case for one of the two top compounds. Although the $\dot{W}_{N E T}$ mean value of decafluorobutane (Compound 1) and octafluorocyclobutane (Compound 2) are very close to each other, the 95\%-confidence 
interval of decafluorobutane (Compound 1) is overlapping with the 95\%-confidence interval of the base case (see Figure 8). This can also be seen in Figure 9, where the ranking was made according to the lower bound of the 95\%-confidence interval, as decafluorobutane is not anymore at the top. Hence, the uncertainty analysis provides important additional information for the interpretation of the results. Based on the analysis of this study, the best performing compounds with the smallest uncertainty range is in fact octafluorocyclobutane (Compound 2). However, the study also implies that more reliable property data for decafluorobutane (Compound 1) is needed.

There are two major causes for large net power output uncertainty:

(1) The input property uncertainty of one or more parameters is high thus resulting in a large net power output uncertainty. This is directly related to the reliability of the measured and predicted property data.

(2) The cycle is operated in a sensitive region in terms of the fluid properties with respect to the model evaluation for a particular fluid. Hence, small variations of the parameters have a large impact on the model output. The knowledge of whether a fluid is sensitive to the ORC model structure or not is a priori unknown. Therefore, an uncertainty analysis of the model output with respect to the fluid properties can give vital information. However, only a global sensitivity analysis of the property parameters with respect to the net power output can provide an in-depth investigation of the overall influence of a particular fluid parameter value to the model output, which is beyond the scope of this study.

The range of uncertainty can be considered as a novel criterion in model based working fluid selection. The narrower the 95\%-confidence interval, the more reliable the property data and the 
less sensitive the fluid performs in the cycle. This information is vital for further detailed modeling and experimental validation studies of identified promising fluids. 


\section{Conclusion}

The study presented a methodology to select working fluids for ORCs considering uncertainty of fluid property estimations. The uncertainty values were taken from DIPPR AIChE database including both experimental measurements and property prediction methods (e.g. GC methods). The fluid property uncertainty was propagated using the Monte Carlo procedure to estimate the net power output uncertainty. Furthermore, a large amount of compounds from the DIPPR database were screened and subsequently the uncertainty analysis method was applied.

The following are the main conclusions from the systematic screening and the uncertainty analysis:

- The uncertainty analysis with respect to the input property uncertainty is a vital tool for ORC model analysis.

- The Monte Carlo based procedure can be applied to propagate fluid property uncertainty to the model output, independent of the process and property models.

- Calculating the net power output including its 95\%-confidence interval for each fluid, gives an additional quantitative criterion for the fluid selection assessing fluid data uncertainty and model sensitivity.

- The ranking of working fluids can be significantly different based whether the mean value or uncertainties (e.g. the lower bound of the 95\%-confidence interval) of the net power output are used. 
- In this study the screening of working fluid candidates identified octafluorocyclobutane as the best performing working fluid with smallest model output uncertainty.

We suggest that future ORC working fluid studies should take into account fluid property uncertainty as a tool to base any kind of fluid investigation, comparison or selection on a thorough property and process model analysis. 


\section{SUPPORTING INFORMATION}

The Supporting Information is available on the website.

Detailed ORC and property model description. List of all feasible compounds including the calculated net power output and the corresponding uncertainties.

\section{AUTHOR INFORMATION}

\section{Corresponding Author}

*Tel.: +45 45252806, E-mail address: gsi@kt.dtu.dk

\section{Author Contributions}

The manuscript was written through contributions of all authors. All authors have given approval to the final version of the manuscript.

\section{Funding Sources}

This work was funded by the Innovation Fund Denmark under the THERMCYC project.

\section{NOMENCLATURE}

Acronymns

$\begin{array}{ll}\text { GMoP } & \text { good modeling practices } \\ \text { CAMD } & \text { computer aided molecular design } \\ \text { EoS } & \text { equation of state } \\ \text { CoMT-CAMD } & \text { continuous molecular targeting computer aided molecular design } \\ \text { PC-SAFT } & \text { perturbed chain statistical associating fluid theory } \\ \text { QSPR } & \text { quantitative structure-property relationships }\end{array}$




$\begin{array}{ll}\text { ORC } & \text { organic Rankine cycle } \\ \text { GWP } & \text { global warming potential } \\ \text { LFL } & \text { lower flammability limit }\end{array}$

Symbols

\begin{tabular}{|c|c|}
\hline$P$ & pressure [bar] \\
\hline $\mathrm{R}$ & ideal gas constant $[\mathrm{J} /(\mathrm{molK})$ \\
\hline $\mathrm{T}$ & temperature $[\mathrm{C}]$ \\
\hline $\mathrm{Vm}$ & molar volume $[\mathrm{m} 3 / \mathrm{mol}]$ \\
\hline$\alpha$ & parameter of Peng-Robinson equation of state \\
\hline $\mathrm{m}$ & parameter of Peng-Robinson equation of state \\
\hline $\mathrm{b}$ & parameter of Peng-Robinson equation of state \\
\hline$\omega$ & acentric factor [-] \\
\hline $\mathrm{T}_{\mathrm{r}}$ & reduced temperature [-] \\
\hline $\mathrm{P}_{\mathrm{c}}$ & critical pressure [bar] \\
\hline $\mathrm{T}_{\mathrm{c}}$ & critical temperature [C] \\
\hline$\dot{W}_{N E T}$ & net power output [kW] \\
\hline MW & molecular weight [g/mol] \\
\hline A & constant of temperature dependent heat capacity $[\mathrm{J} / \mathrm{molK}]$ \\
\hline B & constant of temperature dependent heat capacity $[\mathrm{J} / \mathrm{molK}]$ \\
\hline $\mathrm{C}$ & constant of temperature dependent heat capacity $[\mathrm{J} / \mathrm{molK}]$ \\
\hline $\mathrm{D}$ & constant of temperature dependent heat capacity $[\mathrm{J} / \mathrm{molK}]$ \\
\hline $\mathrm{E}$ & constant of temperature dependent heat capacity $[\mathrm{J} / \mathrm{molK}]$ \\
\hline$c_{p}(T)$ & temperature dependent heat capacity [J/(mol K)] \\
\hline$P_{t}$ & turbine inlet pressure [bar] \\
\hline $\mathrm{T}_{\mathrm{t}}$ & turbine inlet temperature [C] \\
\hline $\mathrm{m}_{\mathrm{wf}}$ & working fluid mass flow [kg/s] \\
\hline
\end{tabular}




$\begin{array}{ll}\text { CDF } & \text { cumulative distribution function } \\ \mathrm{h}_{\mathrm{i}} & \text { specific enthalpy at position i }[\mathrm{kJ} / \mathrm{kg}] \\ \mathrm{d} & \text { dummy variable }\end{array}$

Subscripts and superscripts

critical

i

position in the cycle

$\mathrm{t}$

turbine

wf

working fluid

p constant pressure

r reduced

m molar

NET net 


\section{REFERENCES}

[1] Invernizzi CM. The Organic Rankine Cycle. Closed Power Cycles, Thermodyn. Fundam. Appl., London: Springer Verlang; 2013, p. 117-76.

[2] Dong Q, Chirico RD, Yan X, Hong X, Frenkel M. Uncertainty Reporting for Experimental Thermodynamic Properties. J Chem Eng Data 2005;50:546-50.

[3] Hukkerikar AS, Sarup B, Ten Kate A, Abildskov J, Sin G, Gani R. Group-contribution+ $(\mathrm{GC}+)$ based estimation of properties of pure components: Improved property estimation and uncertainty analysis. Fluid Phase Equilib 2012;321:25-43.

[4] Frutiger J, Marcarie C, Abildskov J, Sin G. A comprehensive methodology for development, parameter estimation, and uncertainty analysis of group contribution based property models - an application to heat of combustion. J Chem Eng Data 2016;61:60213.

[5] Sin G, Gernaey K V., Eliasson Lantz A. Good Modeling Practice for PAT Applications: Propagation of Input Uncertainty and Sensitivity Analysis. Biotechnol Prog 2009;25:1043-53.

[6] Ng LY, Chong FK, Chemmangattuvalappil NG. Challenges and opportunities in computer-aided molecular design. Comput Chem Eng 2014;81:115-29. doi:10.1016/j.compchemeng.2015.03.009.

[7] Maranas C. Optimal molecular design under property prediction uncertainty. AICHE J 1997;43:1250-64.

[8] Kim K-J, Diwekar UM. Efficient Combinatorial Optimization under Uncertainty. 1. Algorithmic Development. Ind Eng Chem Res 2002;41:1276-84.

[9] Martín M, Martínez A. Addressing Uncertainty in Formulated Products and Process Design. Ind Eng Chem Res 2015;54:5990-6001.

[10] Ng LY, Chemmangattuvalappil NG, Ng DKS. Robust chemical product design via fuzzy optimisation approach. Comput Aided Chem Eng 2014;34:387-92.

[11] Ten JY, Hassim MH, Chemmangattuvalappil N, Ng DKS. A Novel Chemical Product Design Framework with the Integration of Safety and Health Aspects. J Loss Prev Process Ind 2015;40:67-80.

[12] Bao J, Zhao L. A review of working fluid and expander selections for organic Rankine cycle. Renew Sustain Energy Rev 2013;24:325-42.

[13] Linke P, Papadopoulos A, Seferlis P. Systematic Methods for Working Fluid Selection and the Design, Integration and Control of Organic Rankine Cycles-A Review. Energies 2015;8:4755-801.

[14] Larsen U, Pierobon L, Haglind F, Gabrielii C. Design and optimisation of organic Rankine cycles for waste heat recovery in marine applications using the principles of natural selection. Energy 2013;55:803-12.

[15] Chys M, Broek M Van Den, Vanslambrouck B, Paepe M De. Potential of zeotropic 
mixtures as working fl uids in organic Rankine cycles. Energy 2012;44:623-32.

[16] Andreasen JG, Larsen U, Knudsen T, Pierobon L, Haglind F. Selection and optimization of pure and mixed working fluids for low grade heat utilization using organic Rankine cycles. Energy 2014;73:204-13.

[17] Luo D, Mahmoud A, Cogswell F. Evaluation of Low-GWP fluids for power generation with Organic Rankine Cycle. Energy 2015;85:481-8. doi:10.1016/j.energy.2015.03.109.

[18] Rödder M, Neef M, Laux C, Priebe KP. Systematic fluid selection for organic Rankine cycles (ORC) and performance analysis for a combined high and temperature low temperature cycle. Proc ASME Turbo Expo 2015 Turbine Tech Conf Expo 2015;138:1-9.

[19] Lemmon E, Huber M, McLinden M. Reference fluid thermodynamic and transport properties-REFPROP, standard reference database 23, version 8.0, National Institute of Standard and Technology; 2007.

[20] Brown JS, Brignoli R, Daubman S. Methodology for estimating thermodynamic parameters and performance of working fluids for organic Rankine cycles. Energy 2014;73:818-28.

[21] Brown JS, Brignoli R, Quine T. Parametric investigation of working fluids for organic Rankine cycle applications. Appl Therm Eng 2015;90:64-74.

[22] Stijepovic MZ, Linke P, Papadopoulos AI, Grujic AS. On the role of working fluid properties in Organic Rankine Cycle performance. Appl Therm Eng 2012;36:406-13.

[23] Zhai H, Shi L, An Q. Influence of working fluid properties on system performance and screen evaluation indicators for geothermal ORC (organic Rankine cycle) system. Energy 2014;74:2-11.

[24] Desideri A, Gusev S, Broek M Van Den, Lemort V, Quoilin S. Experimental comparison of organic fluids for low temperature ORC systems for waste heat recovery applications 2015;97:460-9.

[25] Hærvig J, Sørensen K, Condra TJ. Guidelines for optimal selection of working fluid for an organic Rankine cycle in relation to waste heat recovery. Energy 2016;96:592-602.

[26] Xu J, Yu C. Critical temperature criterion for selection of working fluids for subcritical pressure Organic Rankine cycles. Energy 2014;74:719-33.

[27] Drescher U, Brüggemann D. Fluid selection for the Organic Rankine Cycle (ORC) in biomass power and heat plants. Appl Therm Eng 2007;27:223-8.

[28] Price SE, Mayor JR. Thermodynamic Design and Comparative Analysis of Rankine, ORC and Kalina Cycles for Low-Cost, Meso-Scale Power Generation Systems. ASME 2008 2nd Int. Conf. Energy Sustain., 2008.

[29] Romanin, Vincent D. Rodriguez A, Jean T, Fereres S. Using the Peng-Robinson Equation of State to Explore Working Fluids for Higher Temperature Organic Rankine Cycles. ASME 2014 Int. Mech. Eng. Congr. Expo. Vol. 6A Energy, 2014.

[30] Project 801, Evaluated Process Design Data, Public Release Documentation, Design Institute for Physical Properties (DIPPR), American Institute of Chemical Engineers 
(AIChE) 2014.

[31] Papadopoulos AI, Stijepovic M, Linke P. On the systematic design and selection of optimal working fluids for Organic Rankine Cycles. Appl Therm Eng 2010;30:760-9.

[32] Papadopoulos AI, Stijepovic M, Linke P, Seferlis P, Voutetakis S. Toward Optimum Working Fluid Mixtures for Organic Rankine Cycles using Molecular Design and Sensitivity Analysis. Ind Eng Chem Res 2013;52:12116-33.

[33] Palma-Flores O, Flores-Tlacuahuac A, Canseco-Melchor G. Optimal molecular design of working fluids for sustainable low-temperature energy recovery. Comput Chem Eng 2015;72:334-49.

[34] Molina-Thierry DP, Flores-Tlacuahuac A. Simultaneous optimal design of organic mixtures and rankine cycles for low-temperature energy recovery. Ind Eng Chem Res 2015;54:3367-83.

[35] Mavrou P, Papadopoulos AI, Seferlis P, Linke P, Voutetakis S. Selection of working fluid mixtures for flexible Organic Rankine Cycles under operating variability through a systematic nonlinear sensitivity analysis approach. Appl Therm Eng 2015;89:1054-67. doi:10.1016/j.applthermaleng.2015.06.017.

[36] Lampe M, Stavrou M, Schilling J, Sauer E, Gross J, Bardow A. Computer-aided Molecular Design in the Continuous-Molecular Targeting Framework using GroupContribution PC-SAFT. Elsevier Ltd; 2015.

[37] McKay MD, Morrison JD, Upton SC. Evaluating prediction uncertainty in simulation models. Comput Phys Commun 1999;17:44-51.

[38] Helton JC. Uncertainty and sensitivity analysis in the presence of stochastic and subjective uncertainty. vol. 57. 1997.

[39] Chandrashekar N, Krishnamurty S. Bayesian evaluation of engineering models. ASME 2002 Int Des Eng Tech Conf Comput Inf Eng Conf 2002;2:993-1002.

[40] Gelman A, Carlin J, Stern H, Rubin D. Bayesian Data Analysis. London: Chapman \& Hall/CRC; 2003.

[41] Helton JC, Davis FJ. Latin hypercube sampling and the propagation of uncertainty in analyses of complex systems. Reliab Eng Syst Saf 2003;81:23-69.

[42] Peng D-Y, Robinson DB. A New Two-Constant Equation of State. Ind Eng Chem Fundam 1976;15:59-64.

[43] Liu W, Meinel D, Wieland C, Spliethoff H. Investigation of hydrofluoroolefins as potential working fluids in organic Rankine cycle for geothermal power generation. Energy 2014;67:106-16.

[44] Pierre D. Essentials of Reservoir Engineering. 2007.

[45] Aly F, Lee L. Self-consistent equations for calculating heat capacity, enthalpy, and entropy the ideal gas. Fluid Phase Equilib 1981;6:169-79.

[46] Knotts T, Wilding WV, Rowley R, Giles N, Congore A. The DIPPR 801 Gold Standard 
Systems Approach to Critical Evaluation of Thermophysical Property Data. 19th Symp. Thermophys. Prop., Boulder: 2015.

[47] IUPAC. Atomic Weights of the Elements 1999. J Phys Chem Ref Data 1999;30:701-12.

[48] Schmidt JW, Carrillo-Nava E, Moldover MR. Partially Halogenated Hydrocarbons CHFCl-CF3, CF3-CH3, CF3-CHF-CHF2, CF3-CH2-CF3, CHF2-CF2-C2F3, CF3-CH2CHF2, CF3-O-CH2; Critical Temperature, Refractive Indices, Surface Tension and Estimates of Liquid, Vapor and Critical Densities. Fluid Phase Equilib 1996:187-206.

[49] Cheng DC-H, McCoubrey JC. The Critical Temperatures of Covalent Fluorides. J Chem Soc 1963:4993-5.

[50] Sotani T, Kubota H. Vapor Pressures and PVT Properties of 1,1,1,3,3-Pentafluoropropane (HFC-245fa). Fluid Phase Equilib 1999:32-355.

[51] Bures M, Majer V, Zabransky M. Modification of Benson method for estimation of idealgas heat capacities. Chem Eng Sci 1981;36:529-37.

[52] Iman R, Conover W. A distribution-free approach to inducing rank correlation among input variables. Commun Stat Part B-Simulation Comput 1982;11:311-34.

[53] MATLAB 2015b, The MathWorks, Inc., Natick, Massachusetts, United States n.d.

[54] Regulation (EC) No 1005/2009 of the European Parliament and of the council. Off J Eur Communities 2000;L 269:1-15. 